Zeszyty Naukowe Szkoły Głównej Gospodarstwa Wiejskiego

Ekonomika i Organizacja Gospodarki Żywnościowej nr 108, 2014: 69-78

Jadwiga Bożek, Janina Szewczyk

Katedra Statystyki Matematycznej

Uniwersytet Rolniczy w Krakowie

\title{
Zróżnicowanie powiatów województwa małopolskiego pod względem poziomu infrastruktury technicznej i społecznej
}

\section{Wstęp}

Urządzenia infrastruktury technicznej i społecznej mają niekwestionowane znaczenie dla rozwoju terenów wiejskich, warunków życia ich mieszkańców, a także modernizacji rolnictwa. Obserwuje się, że im wyższy poziom infrastruktury, tym więcej młodych gospodarzy pozostaje na wsi, są bardziej skłonni do powiększania obszaru gospodarstwa, a dochodowość gospodarstw jest wyższa [Żmija 1997, Bujak 1998]. Z kolei niski stopień infrastruktury hamuje rozwój przedsiębiorczości na wsi i zniechęca inwestorów z zewnątrz do podejmowania działalności gospodarczej, co jeszcze bardziej pogłębia zacofanie terenów słabo rozwiniętych. Zależności te wskazują na potrzebę stałej analizy poziomu infrastruktury wsi polskiej.

$\mathrm{Na}$ przestrzeni ostatnich lat obserwuje się poprawę poziomu infrastruktury w całym kraju, do czego w znacznym stopniu przyczyniły się środki pochodzące ze struktur unijnych. Jednakże potrzeby w tym zakresie ciagle są jeszcze duże.

Celem pracy jest dokonanie analizy porównawczej powiatów województwa małopolskiego pod względem poziomu wyposażenia w infrastrukturę techniczną i społeczną w 2010 roku. Badania wykonano na podstawie danych GUS. Na podstawie metody porządkowania liniowego obiektów wielowymiarowych został przeprowadzony ranking, a następnie podział powiatów na 3 grupy: o najlepszym, średnim i najsłabszym poziomie badanej infrastruktury. Otrzymane w ten sposób grupy są bardzo zróżnicowane pod względem poziomu wyposażenia w poszczególne elementy infrastruktury. Dlatego przeprowadzono również grupowanie powiatów według podobieństwa poziomu badanej infrastruktury. Do grupowania zastosowano metodę eliminacji wektorów w połączeniu z metodą najlepszego wyboru. 


\section{Metoda badawcza}

W badaniach przyjęto następujący zbiór zmiennych (cech) opisujących poszczególne powiaty:

$X_{1}$ - procentowy udział mieszkańców korzystających z wodociaggu,

$X_{2}$ - procentowy udział mieszkańców korzystających z kanalizacji,

$X_{3}$ - procentowy udział mieszkańców korzystających z gazu,

$X_{4}$ - wydatki samorządu w przeliczeniu na 1 mieszkańca,

$X_{5}$ - procentowy udział mieszkańców korzystających ze środowiskowej pomo-

cy społecznej w ogólnej liczbie ludności powiatu,

$X_{6}$ - ludność powiatu przypadająca na 1 przedszkole,

$X_{7}$ - liczba podmiotów gospodarczych wpisanych do rejestru REGON danego powiatu na 10 tys. mieszkańców,

$X_{8}$ - stopa bezrobocia w powiecie.

Wśród wymienionych zmiennych są stymulanty $\left(X_{1}, X_{2}, X_{3}, X_{4}, X_{7}\right.$, ) i destymulanty $\left(X_{5}, X_{6}, X_{8}\right)$. Zmienna jest stymulanta, gdy wyższa jej wartość pozwala zakwalifikować obiekt jako lepszy. W przypadku destymulant wzrost wartości zmiennej łączy się ze spadkiem oceny obiektu.

Dane można przedstawić w postaci macierzy:

$$
X=\left[\begin{array}{cccc}
x_{11} & x_{12} & \ldots & x_{1 n} \\
x_{21} & x_{22} & \ldots & x_{2 n} \\
\ldots & \ldots & \ldots & \ldots \\
x_{m 1} & x_{m 2} & \ldots & x_{m n}
\end{array}\right]=\left[x_{i j}\right]_{i=1, \ldots, m}
$$

gdzie: $x_{i j}$ - wartość $j$-tej cechy (zmiennej) w $i$-tym obiekcie (powiecie).

Przeprowadzono normalizację zmiennych metodą unitaryzacji zerowanej według wzorów:

$$
\begin{aligned}
z_{i j} & =\frac{x_{i j}-\min _{i} x_{i j}}{q_{j}} \text { dla stymulant } \\
z_{i j} & =\frac{\max _{i} x_{i j}-x_{i j}}{q_{j}} \text { dla destymulant }
\end{aligned}
$$

gdzie: $q_{j}=\max _{i} x_{i j}-\min _{i} x_{i j} \quad(j=1,2, \ldots, n)$.

$\mathrm{W}$ ten sposób wszystkie zmienne przyjmują wartości z przedziału $[0,1]$, przy czym wyższa wartość zmiennej oznacza, że dany obiekt jest lepszy pod 
względem tej zmiennej. Następnie obliczono wartość zmiennej syntetycznej dla każdego obiektu [Pociecha i in. 1988]:

$$
W_{i}=\sum_{j=1}^{n} z_{i j}, \quad(i=1,2, \ldots, m)
$$

na podstawie której został przeprowadzony ranking, a w dalszej kolejności podział powiatów na trzy grupy: o najlepszym, średnim i najsłabszym poziomie infrastruktury. Grupę I tworzą powiaty, dla których wartość zmiennej syntetycznej $W_{i}$ jest najwyższa i zawiera się w przedziale $\left\langle\max W_{i}-\frac{1}{3} R ; \max W_{i}\right\rangle$; przedziałem odpowiadającym grupie II jest przedział $\left\langle\min W_{i}+\frac{1}{3} R ; \max W_{i}-\frac{1}{3} R\right)$, a grupie III - przedział $\left\langle\min W_{i} ; \min W_{i}+\frac{1}{3} R\right)$, gdzie $R=\max W_{i}-\min W_{i}$.

Dlakażdego powiatu obliczono ponadto wskaźnik poziomu rozwoju: $P_{i}=\frac{W_{i}}{n}$, gdzie: $n$ - liczba zmiennych [Bożek 2002]. Wskaźnik ten przyjmuje wartości z przedziału $[0,1]$, przy czym większa jego wartość oznacza powiat o wyższym poziomie infrastruktury.

W celu pogrupowania powiatów pod względem podobnego poziomu wyposażenia $\mathrm{w}$ poszczególne zmienne, zastosowano metodę eliminacji wektorów. Aby można było zastosować tę metodę, sprowadzono wartości zmiennych opisujących poszczególne powiaty (tab. 1) do przedziału [0, 1], stosując metodę unitaryzacji zerowanej. Dla znormalizowanych w ten sposób zmiennych wyznaczone zostały miary zróżnicowania między obiektami [Kukuła 1989]:

$$
\varepsilon_{i j}=\frac{\sum_{l=1}^{k}\left|a_{i l}-a_{j l}\right|}{2} \quad(i, j=1, \ldots, n)
$$

gdzie: $\varepsilon_{i j}$ - miara zróżnicowania między obiektem $i$ a obiektem $j$.

Miary zróżnicowania obliczone między wszystkimi obiektami (elementy $\varepsilon_{i j}$ ) tworzą macierz zróżnicowań strukturalnych $E_{0}$.

Oblicza się wartość średniego zróżnicowania między obiektami $\bar{\varepsilon}$ :

$$
\bar{\varepsilon}=\frac{\sum_{i=1}^{n} \sum_{j=1}^{n} \varepsilon_{i j}}{n(n-1)}
$$

i tworzy zerojedynkową macierzy E, której elementy $e_{i j}$ są zdefiniowane następująco: 


$$
e_{i j}=\left\{\begin{array}{lll}
0, & \text { gdy } & \varepsilon_{i j}<\beta \\
1, & \text { gdy } & \varepsilon_{i j} \geq \beta
\end{array} \quad \beta=\bar{\varepsilon}\right.
$$

Do macierzy $E$ stosuje się metodę eliminacji wektorów [Chomątowski, Sokołowski 1978], w wyniku której otrzymuje się homogeniczne grupy obiektów. W metodzie eliminacji wektorów wynik grupowania zależy od wartości $\beta$.

W pracy do wyboru wartości $\beta$ zastosowana została metoda najlepszego wyboru [Wysocki, Wagner 1989] wymagająca wielokrotnego przeprowadzania podziału przy różnych wartościach $\beta_{l} \in[a, b]$,

gdzie: $a=\bar{\varepsilon}-s_{\varepsilon}$,

$$
\begin{aligned}
& b=\bar{\varepsilon} \\
& \varepsilon-\text { średnia arytmetyczna } \mathrm{z} \varepsilon_{i j}, \\
& s_{\varepsilon}-\text { odchylenie standardowe } \mathrm{z} \varepsilon_{i j} .
\end{aligned}
$$

$$
\beta_{l}=a+(l-1) h,
$$

gdzie: $l=1,2, \ldots, L$,

$$
\begin{aligned}
& \beta_{L}=b, \\
& h-\mathrm{krok} .
\end{aligned}
$$

Dla każdego $l$-tego grupowania oblicza się wartość funkcji jakości klasyfikacji $F^{(l)}$ :

$$
F^{(1)}=\sum_{k=1}^{r} F_{l k}, l=1, \ldots, L
$$

gdzie: $F_{l k}-$ wskaźnik jakości pogrupowania $k$-tej zmiennej.

$$
F_{l k}=\frac{s_{k(o) /(n-1)}^{2}}{s_{k(w) /(n-m-1)}^{2}}
$$

gdzie: $m$ - liczba wydzielonych grup przy danym $\beta_{l}$,

$s_{k(o)}^{2} \quad$ - wariancja ogólna $k$-tej zmiennej,

$s_{k(w)}^{2}-$ wariancja wewnątrzgrupowa $k$-tej zmiennej.

Optymalnym podziałem jest podział $l_{0}$, przy którym funkcja $F^{(l)}$ przyjmuje największą wartość: $F^{\left(l_{o}\right)}=\max \left\{F^{(1)}, \ldots, F^{(L)}\right\}$. Odpowiadająca temu podziałowi wartość $\beta=\beta_{l_{0}}$ jest szukaną wartością progową. 


\section{Wyniki badań}

Badania przeprowadzono na podstawie danych GUS przedstawiających wartości wybranych elementów infrastruktury technicznej i społecznej w powiatach województwa małopolskiego w 2010 roku (tab. 1). Dla każdej cechy obliczono średnią arytmetyczna, odchylenie standardowe oraz współczynnik zmienności, a także podano wartość minimalną i maksymalną. Z początkowego zbioru cech

Tabela 1

Wartości poszczególnych zmiennych i ich charakterystyki w powiatach województwa małopolskiego w 2010 roku

\begin{tabular}{|l|c|c|c|c|c|c|c|c|}
\hline \multirow{2}{*}{ Powiaty } & \multicolumn{7}{|c|}{ Cecha } \\
\cline { 2 - 9 } & $X_{1}$ & $X_{2}$ & $X_{3}$ & $X_{4}$ & $X_{5}$ & $X_{6}$ & $X_{7}$ & $X_{8}$ \\
\hline Bocheński & 65,2 & 44,5 & 80,1 & 1084,9 & 7,4 & 2699,8 & 765 & 9,7 \\
\hline Krakowski & 85,0 & 34,3 & 67,4 & 627,1 & 4,4 & 4133,2 & 962 & 10,2 \\
\hline Miechowski & 78,1 & 25,3 & 4,0 & 1173 & 7,6 & 8329,5 & 820 & 11,3 \\
\hline Myślenicki & 59,2 & 33,9 & 53,1 & 852,7 & 8,5 & 2811,7 & 909 & 13,2 \\
\hline Proszowicki & 76,8 & 22,9 & 11,7 & 797,7 & 8,1 & 6200,9 & 687 & 11,5 \\
\hline Wielicki & 83,6 & 37,3 & 80,1 & 608,3 & 5,3 & 3298,9 & 1018 & 11,2 \\
\hline Gorlicki & 35,6 & 41,1 & 71,0 & 1183,5 & 13,8 & 2613,4 & 672 & 12,6 \\
\hline Limanowski & 42,8 & 23,6 & 49,5 & 1207,3 & 13,5 & 4633,6 & 677 & 18,2 \\
\hline Nowosadecki & 43,2 & 25,6 & 49,5 & 730,6 & 15,2 & 4342,4 & 653 & 17,3 \\
\hline Nowotarski & 47,0 & 46,7 & 9,2 & 933,2 & 6,4 & 5024,8 & 747 & 12,3 \\
\hline Tatrzański & 63,3 & 58,3 & 3,2 & 1342,2 & 5,1 & 5461,8 & 1400 & 11,5 \\
\hline Chrzanowski & 97,6 & 62,1 & 70,4 & 759,7 & 6,1 & 3864,8 & 890 & 13,5 \\
\hline Olkuski & 96,9 & 48,1 & 66,8 & 1019,9 & 5,8 & 3671,3 & 1012 & 14,7 \\
\hline Oświęcimski & 96,1 & 54,1 & 78,6 & 879,2 & 5,2 & 2955,9 & 880 & 12,6 \\
\hline Suski & 33,8 & 25,0 & 3,2 & 913,4 & 10,4 & 3192,5 & 892 & 10,3 \\
\hline Wadowicki & 74,5 & 41,2 & 62,8 & 676,1 & 5,5 & 3725,9 & 987 & 12,5 \\
\hline Brzeski & 59,8 & 29,3 & 70,9 & 839,5 & 8,7 & 2349,8 & 627 & 11,8 \\
\hline Dąbrowski & 85,7 & 36,1 & 66,4 & 1155,7 & 13,7 & 3085,8 & 493 & 19,6 \\
\hline Tarnowski & 56,1 & 29,5 & 68,4 & 710,9 & 10,8 & 3335,8 & 529 & 13,5 \\
\hline Max(x) & 97,6 & 62,1 & 80,1 & 1342,2 & 15,2 & 8329,5 & 1400 & 19,6 \\
\hline Min(x) & 33,8 & 22,9 & 3,2 & 608,3 & 4,4 & 2349,8 & 493 & 9,7 \\
\hline Średnia & 67,4 & 37,8 & 50,9 & 920,8 & 8,5 & 3985,9 & 822,1 & 13,0 \\
\hline s(x) & 20,25 & 11,7 & 28,0 & 213,1 & 3,3 & 1428,4 & 206,1 & 2,6 \\
\hline V(x) & 0,30 & 0,31 & 0,55 & 0,23 & 0,39 & 0,36 & 0,25 & 0,20 \\
\hline
\end{tabular}

Źródło: Bank Danych Lokalnych, obliczenia własne. 
usunięte zostały te cechy, dla których wartość współczynnika zmienności była niższa od 20\% (m.in. liczba osób na 1 aptekę, przeciętne wynagrodzenie brutto). Badaniami zostały objęte powiaty województwa małopolskiego z wyłączeniem miast: Krakowa, Tarnowa oraz Nowego Sącza.

$\mathrm{Z}$ danych przedstawionych $\mathrm{w}$ tabeli 1 wynika, że powiaty województwa małopolskiego charakteryzuje znaczne zróżnicowanie pod względem poziomu wyposażenia $\mathrm{w}$ wybrane elementy badanej infrastruktury. $\mathrm{Z}$ wodociągu korzysta od $33,8 \%$ mieszkańców w powiecie suskim do $97,6 \% \mathrm{w}$ powiecie chrzanowskim. Procentowy udział mieszkańców korzystających z kanalizacji wynosi od 22,9\% w powiecie proszowickim do $62 \% \mathrm{w}$ powiecie chrzanowskim. Podobne zróżnicowanie dotyczy wartości pozostałych cech.

Największe zróżnicowanie występuje w przypadku odsetka mieszkańców korzystających z gazu - w powiecie wielickim i bocheńskim $80,1 \%$, a w powiecie suskim i tatrzańskim tylko 3,2\%.

Po unormowaniu zmiennych i obliczeniu dla każdego powiatu wartości zmiennej syntetycznej przeprowadzono ranking, a następnie podział powiatów na trzy grupy: o najwyższym, średnim i najniższym poziomie infrastruktury, zgodnie z podanymi wcześniej wzorami. Dla każdego powiatu został obliczony wskaźnik poziomu rozwoju. Wartości zmiennych po unormowaniu, ranking powiatów, wartości zmiennej syntetycznej, wskaźnik poziomu rozwoju i podział na grupy przedstawia tabela 2 .

Najwyższym poziomem rozwoju (wskaźnik wynosi od 0,613 do 0,760 ) charakteryzują się powiaty sąsiadujące z Krakowem oraz powiaty zachodniej części województwa, gdzie wpływ dużego miasta oraz sąsiedztwo Śląska zapewniającego miejsca dobrze płatnej pracy (często do niedawna w kopalniach) miały zasadniczy wpływ na rozwój infrastruktury.

Największe potrzeby $\mathrm{w}$ badanym zakresie występują w powiatach grupy III: nowosądeckim, limanowskim, proszowickim, suskim i tarnowskim, gdzie wskaźnik poziomu rozwoju przyjmuje wartości dużo niższe: od 0,258 do 0,425. Niskie wartości zmiennych po unormowaniu wskazują na duże potrzeby w tych powiatach.

Podstawą przedstawionego rankingu powiatów jest wartość zmiennej syntetycznej, dlatego w otrzymanych grupach występuje duże zróżnicowanie obiektów pod względem poziomu poszczególnych cech. Przykładowo do grupy I należy powiat tatrzański, w którym tylko 3,2\% mieszkańców korzysta z gazu, gdy w powiatach wielickim i bocheńskim (również należących do grupy I) odsetek korzystających z gazu wynosi 80,1\%. Z kolei wydatki samorządu na 1 mieszkańca w powiecie tatrzańskim wynoszą 1342,2 zł, a w powiecie wielickim 608,3 zł. Dokonano więc grupowania powiatów pod względem podobnego poziomu poszczególnych elementów badanej infrastruktury. Grupowanie przeprowadzono 
Tabela 2

Ranking powiatów, podział na grupy, wartości zmiennych po unormowaniu, wartości zmiennej syntetycznej, wskaźnik poziomu rozwoju

\begin{tabular}{|c|c|c|c|c|c|c|c|c|c|c|}
\hline \multirow{2}{*}{ Skład grup } & \multicolumn{8}{|c|}{ Zmienna } & \multirow{2}{*}{\begin{tabular}{|c|} 
Wartość \\
zmiennej \\
syntetycznej
\end{tabular}} & \multirow{2}{*}{$\begin{array}{c}\text { Wskaźnik } \\
\text { poziomu } \\
\text { rozwoju }\end{array}$} \\
\hline & $x_{1}$ & $x_{2}$ & $x_{3}$ & $x_{4}$ & $x_{5}$ & $x_{6}$ & $x_{7}$ & $x_{8}$ & & \\
\hline \multicolumn{11}{|c|}{ Grupa I } \\
\hline Oświęcimski & 0,98 & 0,80 & 0,98 & 0,37 & 0,93 & 0,90 & 0,43 & 0,71 & 6,08 & 0,760 \\
\hline Olkuski & 0,99 & 0,64 & 0,83 & 0,56 & 0,87 & 0,78 & 0,57 & 0,49 & 5,74 & 0,717 \\
\hline Chrzanowski & 1,00 & 1,00 & 0,87 & 0,21 & 0,84 & 0,75 & 0,44 & 0,62 & 5,72 & 0,715 \\
\hline Bocheński & 0,49 & 0,55 & 1,00 & 0,65 & 0,72 & 0,94 & 0,30 & 1,00 & 5,66 & 0,707 \\
\hline Tatrzański & 0,46 & 0,90 & 0,00 & 1,00 & 0,94 & 0,48 & 1,00 & 0,82 & 5,60 & 0,700 \\
\hline Wielicki & 0,78 & 0,37 & 1,00 & 0,00 & 0,92 & 0,84 & 0,58 & 0,85 & 5,33 & 0,667 \\
\hline Krakowski & 0,80 & 0,29 & 0,83 & 0,03 & 1,00 & 0,70 & 0,52 & 0,95 & 5,12 & 0,640 \\
\hline Wadowicki & 0,64 & 0,47 & 0,78 & 0,09 & 0,90 & 0,77 & 0,54 & 0,72 & 4,90 & 0,613 \\
\hline \multicolumn{11}{|c|}{ Grupa II } \\
\hline Myślenicki & 0,40 & 0,28 & 0,65 & 0,33 & 0,62 & 0,92 & 0,46 & 0,65 & 4,31 & 0,539 \\
\hline Brzeski & 0,41 & 0,16 & 0,88 & 0,32 & 0,60 & 1,00 & 0,15 & 0,79 & 4,30 & 0,538 \\
\hline Gorlicki & 0,03 & 0,46 & 0,88 & 0,78 & 0,13 & 0,96 & 0,20 & 0,71 & 4,15 & 0,518 \\
\hline Dąbrowski & 0,81 & 0,34 & 0,82 & 0,75 & 0,14 & 0,88 & 0,00 & 0,00 & 3,73 & 0,467 \\
\hline Nowotarski & 0,21 & 0,61 & 0,08 & 0,44 & 0,81 & 0,55 & 0,28 & 0,74 & 3,72 & 0,465 \\
\hline Miechowski & 0,69 & 0,06 & 0,01 & 0,77 & 0,70 & 0,00 & 0,36 & 0,84 & 3,44 & 0,430 \\
\hline \multicolumn{11}{|c|}{ Grupa III } \\
\hline Tarnowski & 0,35 & 0,17 & 0,85 & 0,14 & 0,41 & 0,84 & 0,04 & 0,62 & 3,40 & 0,425 \\
\hline Suski & 0,00 & 0,05 & 0,00 & 0,42 & 0,44 & 0,86 & 0,44 & 0,94 & 3,15 & 0,394 \\
\hline Proszowicki & 0,67 & 0,00 & 0,11 & 0,26 & 0,66 & 0,36 & 0,21 & 0,82 & 3,09 & 0,386 \\
\hline Limanowski & 0,14 & 0,02 & 0,60 & 0,82 & 0,16 & 0,62 & 0,20 & 0,14 & 2,70 & 0,337 \\
\hline Nowosądecki & 0,15 & 0,07 & 0,60 & 0,17 & 0,00 & 0,67 & 0,18 & 0,23 & 2,06 & 0,258 \\
\hline
\end{tabular}

Źródło: Obliczenia własne.

metodą eliminacji wektorów na poziomie wartości progowej zróżnicowania $\beta=0,28$ (przy średnim zróżnicowaniu równym 0,3081 ). Otrzymano 5 grup o następującym składzie:

- grupa 1 - powiaty: bocheński, krakowski, myślenicki, wielicki, chrzanowski, olkuski, oświęcimski, wadowicki, brzeski,

- grupa 2 - powiaty: gorlicki, nowosądecki, tarnowski,

- grupa 3 - powiaty: nowotarski, tatrzański,

- grupa 4 - powiaty: limanowski, dąbrowski,

- grupa 5 - powiaty: miechowski, proszowicki.

Powiat suski odbiega od wyodrębnionych grup, tworząc jednoelementową grupę. 
Wartości średnie, odchylenie standardowe, współczynnik zmienności oraz średni wskaźnik poziomu rozwoju dla poszczególnych grup typologicznych zostały przedstawione w tabeli 3 .

Grupa 1 skupia wszystkie powiaty o najwyższym poziomie rozwoju (z wyjątkiem powiatu tatrzańskiego) i dwa powiaty z grupy II: myślenicki i brzeski. Grupę tę charakteryzuje wysoki poziom infrastruktury technicznej, gęsta sieć przedszkoli, umiarkowana (relatywnie) liczba osób korzystających z pomocy społecznej (średnio 6,3\%). Największe potrzeby występują w zakresie kanalizacji, z której korzysta tylko średnio 42\% mieszkańców powiatów tej grupy.

W grupie 2 występuje znacznie niższy odsetek korzystających $\mathrm{z}$ wodociagu (średnio 45\%) i kanalizacji (32\%), wysoki odsetek osób korzystających z pomocy społecznej (średnio 13,3\%) oraz niska przedsiębiorczość (618 podmiotów na 10 tys. mieszkańców).

Grupe 3 charakteryzuje najwyższy poziom przedsiębiorczości (1073 podmioty), najniższy odsetek korzystających z gazu (6,2\%), ale też najniższy odsetek osób korzystających z pomocy społecznej (5,8\%), umiarkowane (relatywnie) bez-

\section{Tabela 3}

Charakterystyki grup powiatów województwa małopolskiego (średnia arytmetyczna, odchylenie standardowe, współczynnik zmienności)

\begin{tabular}{|c|c|c|c|c|c|c|c|c|c|c|}
\hline \multirow{2}{*}{ Grupa } & \multirow{2}{*}{$\begin{array}{c}\text { Charakte- } \\
\text { rystyki }\end{array}$} & \multicolumn{8}{|c|}{ Cechy } & \multirow{2}{*}{$\begin{array}{l}\text { Wskaźnik } \\
\text { poziomu } \\
\text { rozwoju }\end{array}$} \\
\hline & & $x_{1}$ & $x_{2}$ & $x_{3}$ & $x_{4}$ & $x_{5}$ & $x_{6}$ & $x_{7}$ & $x_{8}$ & \\
\hline \multirow{3}{*}{ G1 } & Średnia & 79,8 & 42,8 & 70,0 & 816,4 & 6,3 & 3279,0 & 894,4 & 12,2 & \multirow{3}{*}{0,655} \\
\hline & $s(x)$ & 14,8 & 10,0 & 8,4 & 156,8 & 1,4 & 572,4 & 120,6 & 1,5 & \\
\hline & $V(x)$ & 0,19 & 0,23 & 0,12 & 0,19 & 0,23 & 0,17 & 0,13 & 0,12 & \\
\hline \multirow{3}{*}{ G2 } & Średnia & 45,0 & 32,1 & 63,0 & 875,0 & 13,3 & 3430,5 & 618,0 & 14,5 & \multirow{3}{*}{0,401} \\
\hline & $s(x)$ & 8,5 & 6,6 & 9,6 & 218,3 & 1,8 & 709,0 & 63,4 & 2,0 & \\
\hline & $V(x)$ & 0,19 & 0,21 & 0,15 & 0,25 & 0,14 & 0,21 & 0,10 & 0,14 & \\
\hline \multirow{3}{*}{ G3 } & Średnia & 55,2 & 52,5 & 6,2 & 1137,7 & 5,8 & 5243,3 & 1073,5 & 11,9 & \multirow{3}{*}{0,582} \\
\hline & $s(x)$ & 8,1 & 5,8 & 3,0 & 204,5 & 0,7 & 218,5 & 326,5 & 0,4 & \\
\hline & $V(x)$ & 0,15 & 0,11 & 0,48 & 0,18 & 0,11 & 0,04 & 0,30 & 0,03 & \\
\hline \multirow{3}{*}{ G4 } & Średnia & 64,3 & 29,9 & 58,0 & 1181,5 & 13,6 & 3859,7 & 585,0 & 18,9 & \multirow{3}{*}{0,402} \\
\hline & $s(x)$ & 21,5 & 6,3 & 8,5 & 25,8 & 0,1 & 773,9 & 92,0 & 0,7 & \\
\hline & $V(x)$ & 0,33 & 0,21 & 0,15 & 0,02 & 0,01 & 0,20 & 0,16 & 0,04 & \\
\hline \multirow{3}{*}{ G5 } & Średnia & 77,5 & 24,1 & 7,9 & 985,4 & 7,9 & 7265,2 & 753,5 & 11,4 & \multirow{3}{*}{0,408} \\
\hline & $s(x)$ & 0,7 & 1,2 & 3,9 & 187,7 & 0,3 & 1064,3 & 66,5 & 0,1 & \\
\hline & $V(x)$ & 0,01 & 0,05 & 0,49 & 0,19 & 0,03 & 0,15 & 0,09 & 0,01 & \\
\hline G6 & $\begin{array}{l}\text { Powiat } \\
\text { Suski }\end{array}$ & 33,8 & 25 & 3,2 & 913,4 & 10,4 & 3192,5 & 892 & 10,3 & 0,394 \\
\hline
\end{tabular}

Źródło: Obliczenia własne. 
robocie $(11,9 \%)$ i niewielka liczba przedszkoli. Wysoki w porównaniu z innymi grupami jest tutaj poziom wydatków przypadających na 1 mieszkańca (1137 zł), co może w przyszłości przyczynić się do wzrostu poziomu infrastruktury.

Grupa 4 odbiega od pozostałych najwyższym bezrobociem (18,9\%). Najwyższy jest tu również odsetek osób korzystających z pomocy społecznej $(13,6 \%)$ i najniższa przedsiębiorczość (585 podmiotów gospodarczych na 1000 mieszkańców). Relatywnie wysokie wydatki na 1 mieszkańca (1181,5 zł) mogą w przyszłości wpłynąć na poprawę infrastruktury.

W grupie 5 największe są potrzeby w zakresie kanalizacji i gazu. Tylko $24 \%$ mieszkańców korzysta z kanalizacji i niespełna $8 \%$ z gazu. Na 1 przedszkole przypada najwięcej osób w porównaniu z pozostałymi grupami - 7265 .

\section{Podsumowanie i wnioski}

1. Powiaty województwa małopolskiego charakteryzuje duże zróżnicowanie pod względem poziomu wybranych elementów infrastruktury technicznej i społecznej. Procentowy udział korzystających $\mathrm{z}$ wodociagu waha się od 33,8\% mieszkańców (powiat suski) do 97,6\% (powiat chrzanowski). Dostęp do kanalizacji ma od 23\% mieszkańców (powiat proszowicki) do 62\% (powiat chrzanowski). Jeszcze większe zróżnicowanie występuje w przypadku odsetka mieszkańców korzystających z gazu - od około 3\% (powiaty suski i tatrzański) do $80 \%$ mieszkańców (powiaty wielicki i bocheński).

2. Najwyższy poziom pod względem badanych cech w 2010 roku osiagnę̧y powiaty: oświęcimski, olkuski, chrzanowski, bocheński, tatrzański, wielicki, krakowski i wadowicki. W grupie II, o średnim poziomie, znajdują się powiaty: myślenicki, brzeski, gorlicki, dąbrowski, nowotarski i miechowski. Do grupy o najniższym poziomie należy 5 powiatów: tarnowski, suski, proszowicki, limanowski oraz nowosądecki.

3. W wyniku grupowania powiatów pod względem podobnego poziomu poszczególnych elementów badanej infrastruktury otrzymano 5 grup oraz jeden obiekt izolowany, odbiegający od wyodrębnionych grup (powiat suski). Grupa pierwsza skupia 9 powiatów o najwyższym poziomie rozwoju: bocheński, krakowski, myślenicki, wielicki, chrzanowski, olkuski, oświęcimski, wadowicki i brzeski. W powiatach tych największe potrzeby występują w zakresie kanalizacji, do której dostęp ma średnio tylko około 43\% mieszkańców. Druga grupa obejmuje 3 powiaty: gorlicki, nowosądecki i tarnowski, gdzie poprawy wymaga sytuacja $\mathrm{w}$ zakresie dostępu do wodociagu, kanalizacji, liczby osób korzystających z pomocy społecznej, a także poziom przedsiębiorczości. Kolejne trzy grupy, z których każda jest dwuelementowa, charakteryzuja się jeszcze niższym wskaźnikiem poziomu rozwoju. 
4. Z przeprowadzonych analiz można wnioskować, że pomiędzy powiatami występują wyraźne różnice w poziomie rozwoju infrastruktury technicznej i społecznej, a potrzeby takich powiatów jak nowosądecki, limanowski czy suski są w tym zakresie jeszcze bardzo duże.

\section{Literatura}

BOŻEK J., 2002: O niektórych metodach porzadkowania liniowego, Wiadomości Statystyczne 9, s. 10-16.

BUJAK T., 1998: Infrastruktura wsi polskiej w aspekcie integracji Polski z Uniq Europejska, Zeszyty Naukowe AR w Krakowie, Seria Sesja Naukowa 55, s. 223-230.

CHOMĄTOWSKI S., SOKOŁOWSKI A., 1978: Taksonomia struktur, Przegląd Statystyczny 2, s. 217-226.

KUKUŁA K., 1989: Statystyczna analiza strukturalna i jej zastosowanie w sferze ustug produkcyjnych dla rolnictwa, Zeszyty Naukowe AE w Krakowie, Seria specjalna „Monografie" 89, Kraków.

POCIECHA J., PODOLEC B., SOKOŁOWSKI A., ZAJĄC K., 1988: Metody taksonomiczne w badaniach społeczno-ekonomicznych, PWN, Warszawa.

WYSOCKI F., WAGNER W., 1989: O ustalaniu wartości progowej zróżnicowania struktur $z$ danych empirycznych, Wiadomości Statystyczne 9, s. 18-20.

ŻMIJA J., 1997: Infrastruktura techniczna jako element wielofunkcyjnego rozwoju wsi w Matopolsce, Zeszyty Problemowe Postępów Nauk Rolniczych 445, s. 65-73.

\section{Diversity of districts of Małopolskie region with respect to technical and social infrastructure}

\section{Abstract}

The paper presents results comparison of districts within Małopolskie region with respect to the chosen features of technical and social infrastructure in 2010. On the basis of the method of linear ordering of multidimensional objects the ranking arrangement has been carried out and then the division of districts into three groups: of high, moderate and low level of the infrastructure being investigated. The districts were grouped according to the level of equipment in certain items of infrastructure. For the grouping the method of vector elimination has been applied. 